\title{
Effectiveness of The Rural Community Health Practice Carried Out In Nabweru Sub-County, Wakiso District.
}

\author{
Shafic Kiberua,1, Sulaiman Mahmood Kakoozaa \\ a Uganda Institute of Allied Health and Management Sciences-Mulago, \\ P.O. Box 34025, Kampala, Uganda
}

\begin{abstract}
\end{abstract}

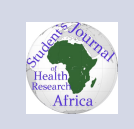

Background:

The field report was about the effectiveness of the rural community health practice to prove whether it's viable to the people in the community. The Objectives of the study was to gain more practical experience in the field, to acquire more knowledge in environmental health, to put theoretical knowledge into practice, and to enable the community to practice proper sanitation and hygiene. The field study was carried out in approximately two months from 16th|/July/2014 to 5th/September/2014.

\section{Methodology}

I reported at the organization on 17th July 2014 and was received by the District Health Inspector who later introduced him to the office public department.

I received orientation in the office of the District Health Inspector for about a week and then later was sent to the sub-county for the rest of the period. I was assigned to the public health department of the Nabweru sub-country in the Wakiso district

\section{Results and observations}

The Organizational structure of Nabweru sub-country was fully understood. I learned better ways of how to deal with the community in many aspects. Skills gained

Included Communication, and Immunization. Problems encountered included those from the organization, the workers and trainee.

\section{Conclusion and recommendation ${ }^{a}$}

The rural community practice was important as it helped to relate what was taught in class to the practical aspect. Therefore, I acknowledge the role-played by the staff of Nabweru Sub-County and the community at large. The sub-county in conjunction with the district should budget for sensitization outreaches in the community

${ }^{a}$ Date submitted: 25-10-2021
Date accepted: 27-10-2021 Email:
kiberushafic@gmail.com

\section{Background to the Field} Study

The field study was about the effectiveness of the rural community health practice to prove whether it's viable to the people in the community.
- To gain more practical experience in the field

- To acquire more knowledge in environmental health

- To put theoretical knowledge into practice

- To enable the community to practice proper sanitation and hygiene 


\section{Scope of the study Geographical location}

The area of the field practice was Nabweru subcountry, Wakiso district under the public health department. The area was located $4 \mathrm{~km}$ north of Kampala city along Kampala Bombo highway linking Uganda to its northern neighbor, like Sudan .it is surrounded by Nansana town council and Gombe sub-country (Ug et al., no date).

The sub-country has five parishes, that is; Wamala, Kawanda, Nakyesanjja, Kawempe, and Maganjo; it has the following departments, community development, administration, finance, and planning then lastly public health department (Ug et al., no date).

\section{Duration of the study}

The field study was carried out in approximately two months from 16th|/July/2014 to 5th/September/2014.

\section{Organization background (office of attach- ment)}

The public health department was the office of attachment in Nabweru Sub-County under Wakiso district.

It comprises staff members, that is to say, health inspectors and health assistants.

They try their level to emphasize the promotion of the practice through preventing the community against several communicable diseases. It's done through proper disposal of solid waste, human excreta, practicing good storage, collection, transportation of refuse and immunization, and many others

\section{Management of the Field}

\section{Role of UIAHMS - Mulago.}

- To give the students theoretical knowledge, and practical skills which perfect them to manage communities of different social community backgrounds.

- To supervise students during their field practice.

- To prepare and provide introduction letters to students for their attachment.

\section{Reporting in the organization}

I reported at the organization on 17th July 2014 and was received by the District Health Inspector who later introduced him to the office public department.

I received orientation in the office of the District Health Inspector for about a week and then later was sent to the sub-county for the rest of the period.

The department to which the trainee was assigned

I was assigned to the public health department of the Nabweru sub-country in the Wakiso district

\section{Duties of the department}

1. To approve building plans after a site inspection is carried out.

2. To ensure that health standards at the workplace and home are promoted.

3. To ensure health promotion in school this is done by regular inspection of the school to prove whether they have sanitary facilities as well as good management refuse.

4. To ensure refuse is collected and managed well

5. To identify nuisances and serve them with notices.

6 . To educate the community on a health matter, for example, all food handlers must have the following items, valid medical certificates, indicating that they are free to handle food, closed shore, aprons, fingernails must be short.

7. To hold meetings with local leaders and chiefs to discuss issues related to health.

8. To do regular inspection of the premises and making follow up.

\section{Head of department}

The department was headed by Mrs. Nanyanzi Fatumah the District Health Inspector

The responsibilities the trainee was assigned

- Surveying on solid waste management in Wamala parish

- To inspect restaurants, schools, guest houses, markets, hotels, industries, and households

\subsection{Worked with the following people}

Mrs Nanyanzi Fatumah (District Health Inspector

Mrs Namukabya Josephine (Health Assistant

Mr Kakooza Sulaiman Mahmood (Supervisor

\section{Relationship with other officers Law enforcement}

During the occurrence of any nuisance, for instance, filled up pit latrine in schools, homestead, and markets. we went with the law enforcement officer to ensure observation of peace as well as setting order.

\section{Physical planner}

We moved together on the community for site inspection and thereafter the plan was approved 
.and even registered them in the building plan register book.

\section{The role of the work supervisors}

- To follow up, supervise laborers who are in charge of various activities, for example, cleaning, and garbage collection

- To supervise various activities in villages related to health promotion

- Provide protective gears to be used in cleaning and garbage collection to the, casual laborers

- To health educate casual laborers on garbage collection and protective measures against injuries and infections

The role of the school supervisors

- To check whether the student is present in the field

- To guide report writing

- To check on a student in the field to know the activities done in the field

Findings and Observations:

\section{Organizational structure}

\section{New things learned from the office}

Learned better ways of how to deal with the community in many aspects

Learned how to effectively health educate the people in the community

Even how to work with different professionals in various offices

\section{Skills gained}

Communication, and immunization

Will use the skills gained to improve the sanitation of the community members

\section{Personal contributions to the organization}

I helped in the activity of immunizing together with the health workers at the health center

Problems encountered during the study that affected the work of,

The organization

- Luck of funds

- Luck of structures

The workers

- Luck of transport

- Luck of cooperation from the politicians

\section{The trainee}

- Long distances

- Language barrier

Activities, Challenges, and Recommendations

Community health management
Health education and sensitization were done on human waste management to prevent diseases in Wamala parish.

\section{Point talked about}

- Educate the community on the dangers of open dumping of the excreta

- Talked about ecological sanitation which lasts longer

- To have well practices of hand cleaning

\section{Inspection}

In the Nabweru sub-country, the health assistant carries out an inspection on activities that comprises of the following activities and the following are the activities we carried out during the inspection. Inspection of the sanitary facilities for example the pit latrines, sock pits, and also other facilities like the eating places, salons, drug shops,

We also went to the parishes for the issue of a general facelift of the buildings/premises following cap 281 of the public health act. In the note, the following activities were to be done by the people is not more than seven days.

- Repair then defective floor

- Provision of the ceiling

- Plastering and painting the walls

- Removal of debris within and around the building

- The Provision of dust bins

- And construction of sock pits and stop the act of discharging wastewater to the environment

\section{Immunization}

During the field study, immunization was carried out by medical personal together with the trainee using the new vaccine known as the PCV that was given to children.

\section{Challenges of immunization}

- We walked long distances because we had to move from house to house

- Language barrier

- Lack of transport

-Wrong cultural belief the babies excreta is not dumped in the pit latrine

\section{Recommendation}

The sub-county in conjunction with the district should budget for sensitization outreaches in the community

\section{Home improvement}

At the time of inspection same premises were found sound with all the requirements of a good home. 


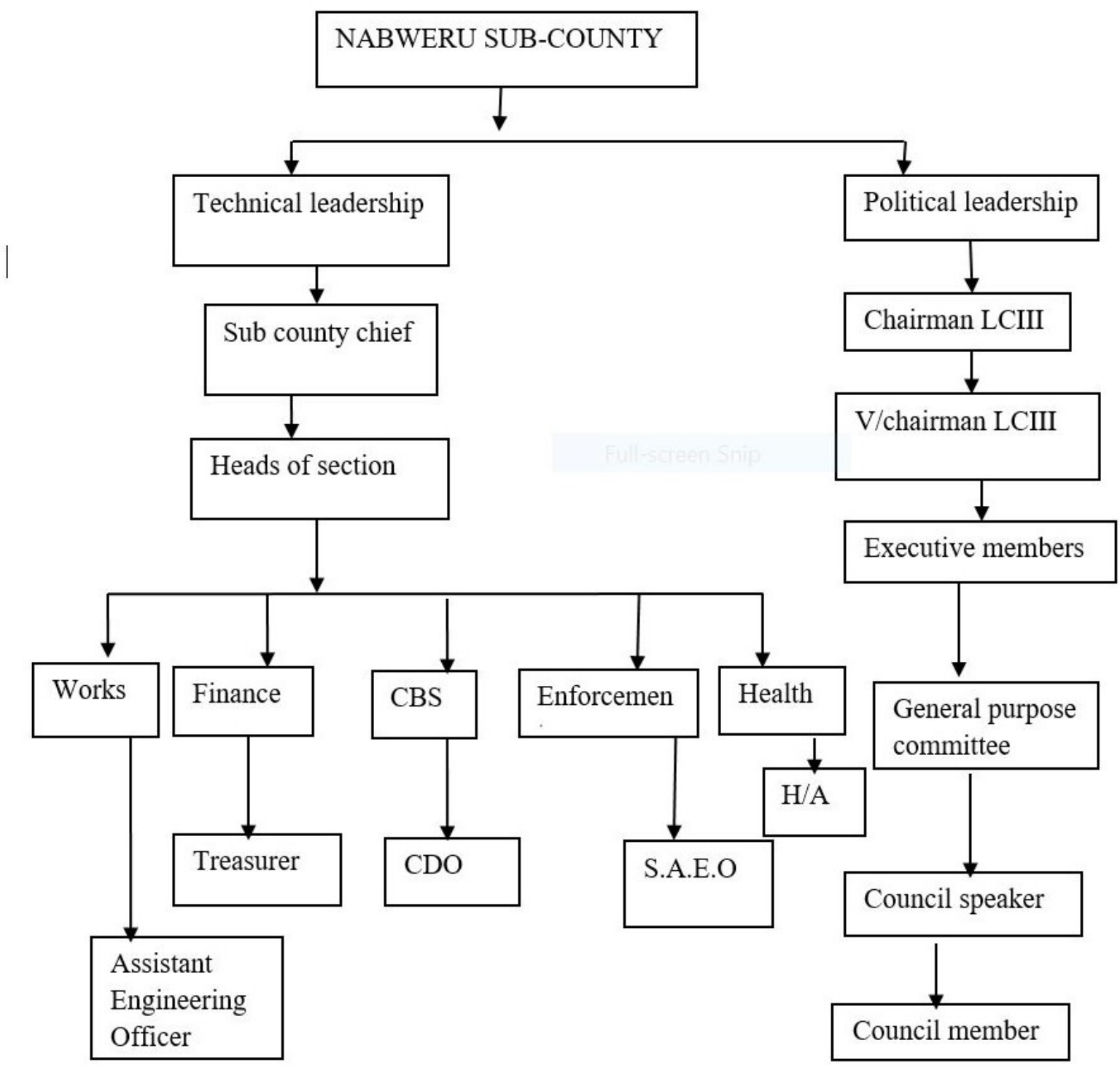

Figure 1. Organizational structure

Residential buildings were visited in the parish and it was found that few people were found without latrines in the parish.

Some homes in the parish were found with latrines except owners were sharing with neighbors.

In many homes, hand washing facilities and anal cleansing materials were absent in the latrines.

\section{CHALLENGES}

- Lack of transport

- Language barrier

\section{Recommendations}

- VHTs should continue encouraging home members to put anal cleansing materials, tippy taps and make use of them after latrine activities.

- Those without latrines were given 30 days to have put them in place
- Prizes should be given to the cleanest homes and village level as one way of motivation.

\section{Health Education}

Health education was carried out by the trainee and it was mainly to OPD patients, attendants.

Health education is on;

- Completing doses prescribed.

- Personal hygiene.

- Excreta management.

\section{Achievements}

- There was a gradual behavioral change in hygiene and sanitation practices in the community.

- Hand washing was made at the health facility.

\section{Challenges}

- Clients come to the health facility late hence missing health education talk in the morning.

- Inadequate teaching-learning aids. 


\section{Recommendation}

- The sub-county in conjunction with the district should budget for sensitization outreaches in the community.

- The sub-county should also budget for the teaching materials that are used during the heath talk.

\section{Vector and vermin control}

We had a workshop on how to use the (LLIN) long last sting insect side treated nets.

It was held at Nansana town council. We also trained the village health team I (VHTs) at the kawanda health center. Kawanda as a parish in Nabweru Sub County has three villages and each village had four VHTs and was trained twelve VHTs

\section{Challenge}

- Registration time was not enough

- Some community members had a negative attitude towards the activity because they had registered previously and missed

- Other community members deliberately refused to register

- Lack of transport to move from one village to another

\section{Recommendation}

The sub country should budget and organize talks to the community members about the (LLIN)

Evaluation

- This was done every day after a day's work, with weekly and monthly reports.

- This was done depending on implemented planned activities and those not yet implemented.

The assessment of the field study in the organization

The organization ensure that there is maximum operation among their members for example all categories of workers, punctuality is maintained so that, staff carry out the activities effectively

\section{The department of the field}

Public health was the department of my field study which is found in Nabweru Sub County in Wakiso district

Recommendation for the identified problem

- Public health as a department should be given vehicles to overcome the problem of transport

- The government should fund public health with money

\section{Department of the field study.}

The rural community practice was comprehensive and experienced since the trainee tried to complete all the work assigned to him by the work supervisor and school supervisor in one and half month period.

Due to the large area and big population in Nabweru Sub County, this offered a good opportunity for rural community practice.

The Public Health department was aimed at improving the sanitation and hygiene levels in the community through;

- Promoting food and personal hygiene.

- Ensuring regular refuse disposal.

- Provision of safe water.

\section{Comments on the findings}

During the stay of the trainee at Nabweru SubCounty, the following were noticed in the Public Health department;

- Delays in the release of funds for PHC activities.

- Inadequate facilitation or funding sanitation activities.

Recommendations for the identified problems.

The following should be put into consideration in Nabweru Sub-County;

\section{The Sub-County}

- Sub-County and DHO's office should supervise workers to improve the quality of services.

- The Sub-County should motivate VHTs by giving them incentives.

- Introduction of capacity buildings workshops to bridge the gap amongst staff.

- Refresh training to VHTs.

- Serious action to schools that do not meet minimum requirements.

\section{The local authority}

- Adequate allocation of funds to the Public Health department.

- Early release of PHC funds to enable timely running of activities.

- Ensure enforcement of the Public Health Act.

\section{The community}

- Formulation of sanitation communities.

- Hold regular meetings to discuss matters concerning water and sanitation.

\section{Prediction trend for improvement}

- Nabweru Sub-County can achieve its goal if the emphasis is put on the collaboration within the different departments especially the political side and following the good politics in the place

- There will be an improvement if the abovementioned points are into consideration thank God that all the activities that I did in the fieldwork on smoothly as related to the outline objectives of the 
study. I gained a lot of experience during my study. The field this was because I gained a lot of experience.

\section{Conclusion}

To conclude, the rural community practice was important as it helped to relate what was taught in class to the practical aspect. Therefore, I acknowledge the role-played by the staff of Nabweru SubCounty and the community at large.

\section{Acknowledgment}

I wish to express my gratitude and appreciation for the support that was accorded to me during the preparation of this report. This goes to the supervisor of Wakiso District, Mrs. Namukabya Josephine, Miss Kyamulibwa Azizah, Mrs. Nanyanzi Fatumah for the support rendered to me hence achieving this important report in my academic career.

List of abbreviations:

CBS Community Based Service

DHO District Health Officer

H/C II Health Centre Two

H/A Health Assistant

PHC Primary Health Care

SACEO Senior Assistant Enforcement Officer

UIAHMS Uganda Institute of Allied Health and Management Sciences -Mulago

VHT Village Heath Team

\section{References:}

1. Ug, W.D.D.D. location in et al. (no date) Wakiso District - Wikipedia. Available at: https://en.wikipedi a.org/wiki/Wakiso_District (Accessed: 20 November 2021). 